
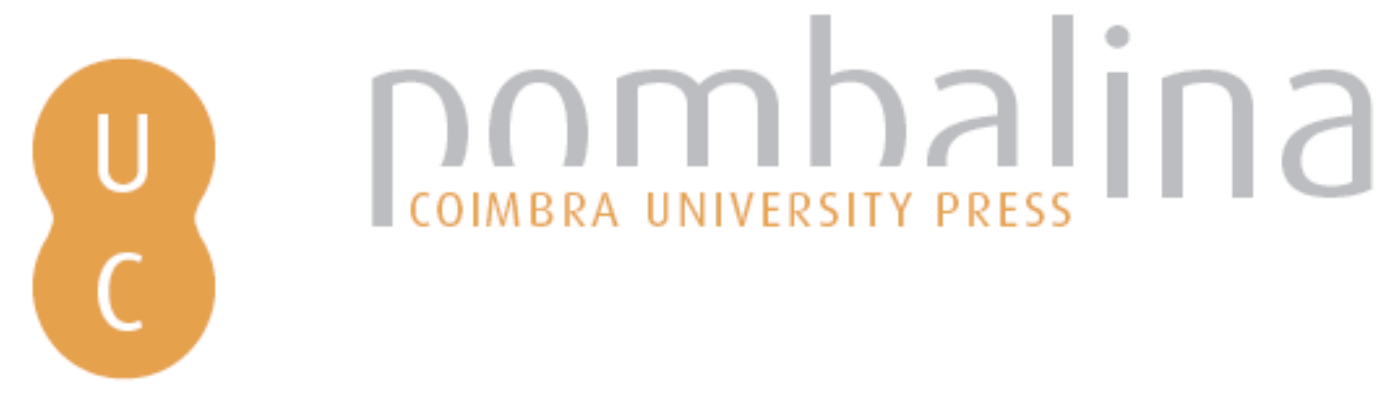

\title{
O papel das práticas quotidianas das famílias na definição de comunidades sustentáveis à escala urbana
}

Autor(es): $\quad$ Louro, Ana; Costa, Eduarda Marques da; Silva, Soraia

Publicado por: Imprensa da Universidade de Coimbra

URL

persistente: URI:http://hdl.handle.net/10316.2/30806

DOI: $\quad$ DOI:http://dx.doi.org/10.14195/978-989-26-0244-8_34

Accessed : $\quad$ 26-Apr-2023 16:16:30

A navegação consulta e descarregamento dos títulos inseridos nas Bibliotecas Digitais UC Digitalis, UC Pombalina e UC Impactum, pressupõem a aceitação plena e sem reservas dos Termos e Condições de Uso destas Bibliotecas Digitais, disponíveis em https://digitalis.uc.pt/pt-pt/termos.

Conforme exposto nos referidos Termos e Condições de Uso, o descarregamento de títulos de acesso restrito requer uma licença válida de autorização devendo o utilizador aceder ao(s) documento(s) a partir de um endereço de IP da instituição detentora da supramencionada licença.

Ao utilizador é apenas permitido o descarregamento para uso pessoal, pelo que o emprego do(s) título(s) descarregado(s) para outro fim, designadamente comercial, carece de autorização do respetivo autor ou editor da obra.

Na medida em que todas as obras da UC Digitalis se encontram protegidas pelo Código do Direito de Autor e Direitos Conexos e demais legislação aplicável, toda a cópia, parcial ou total, deste documento, nos casos em que é legalmente admitida, deverá conter ou fazer-se acompanhar por este aviso.

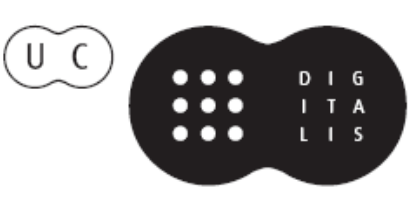




\section{TRUNFOS DE UMA}

\section{EOGRAFIA ACIVA}

\section{DESENVOLVIMENTO LOCAL,}

AMBIENTE,

ORDENAMENTO

E TECNOLOGIA

Norberto Santos

Lúcio Cunha

COORDENAÇÃO 
Ana Louro, Eduarda Marques da Costa, Soraia Silva

Instituto de Geografia e Ordenamento do Território (IGOT) da Universidade de Lisboa

\section{O PAPEL DAS PRÁTICAS QUOTIDIANAS DAS FAMÍLIAS NA DEFINIÇÃO DE COMUNIDADES SUSTENTÁVEIS À ESCALA URBANA}

\section{INTRODUÇÃO}

As premissas da sustentabilidade e a sua relação com as políticas de planeamento territorial estão na base do conceito de Comunidade Sustentável. A sua definição pode, por sua vez, ser descontruída em sete componentes que assumem um conjunto de pressupostos relacionados com o planeamento urbano e com as práticas da populaçáo que constitui a Comunidade.

A presente investigação ${ }^{1}$ teve como objectivo central compreender o conceito de Comunidade Sustentável e as suas componentes, de forma a ensaiar uma metodologia de trabalho com base em indicadores que procurassem medir a sustentabilidade à escala das Comunidades. Assim, considerou-se como ponto de partida os bairros, escala que melhor traduz a relaçáo entre os habitantes e os seus espaços de vivência. Dos sete pilares que caracterizam as comunidades sustentáveis, centrou-se a análise nas práticas quotidianas das famílias de dois bairros da AML, através de inquérito [Telheiras, em Lisboa, e Quinta do Conde (daqui em diante QC), em Sesimbra], no que respeita ao padrão de utilização de três serviços e das formas de mobilidade a este associadas.

A comunicação engloba cinco pontos: em primeiro lugar um breve enquadramento teórico e de seguida a metodologia aplicada; no terceiro ponto, é feita uma breve contextualização dos bairros; o quarto corresponde à análise dos padrôes de procura de bens / serviços e o último às reflexóes.

\section{OS FUNDAMENTOS - CONCEITO DE COMUNIDADE SUSTENTÁVEL}

O conceito de Cidades Sustentáveis na óptica do planeamento urbano surgiu nos anos 90 do século XX nos EUA e na Europa, em oposição à aplicação dos princípios funcionalistas do Urbanismo Moderno. As referências variam entre documentos elaborados por

\footnotetext{
${ }^{1}$ Projecto elaborado em contexto académico: trabalho para o Seminário de Indicadores de Ordenamento e Desenvolvimento Territorial, mestrado de Gestáo do Território e Urbanismo, IGOT-UL (equipa alargada) e base para projecto de investigação sobre forma urbana sustentável - Projecto de Investigação PTDC/GEO/69109/ /2006 - FURBS).
} 
urbanistas como a Carta do Novo Urbanismo, de 1996 (CNU 2001) e recomendaçóes de génese política como Aalborg+10, de 2004 (Autoridades Locais Europeias, 2004).

A noção de Comunidades Sustentáveis consolidou-se no Reino Unido, no início da década, por via de acção política, onde foi encetado um processo de revisão do conceito e estruturação das suas componentes, para aplicação no planeamento territorial. O relatório final - The Egan Review (ODPM 2004) - serviu assim de base para a investigação.

As Comunidades Sustentáveis são definidas da seguinte forma:

«Sustainable communities meet the diverse needs of existing and future residents, their children and other users, contribute to a high quality of life and provide opportunity and choice. They achieve this in ways that make effective use of natural resources, enhance the environment, promote social cohesion and inclusion and strengthen economic prosperity» (ODPM 2004, p. 18).

As sete componentes associadas ao conceito (Figura 1) resumem de forma eficaz as dimensóes assinaladas na definição.

Figura 1 - Componentes das Comunidades Sustentáveis

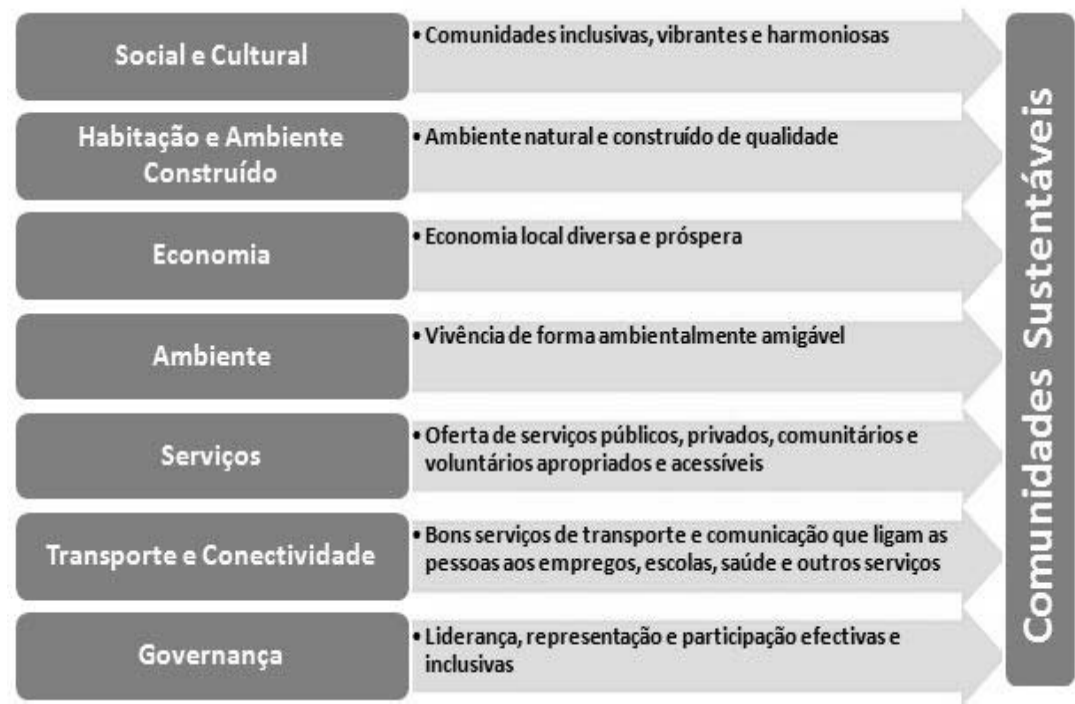

(Elaboração própria - Adaptado de OPDM, 2004, p. 19)

\section{Metodologia}

Para a execução da investigação no seu todo procedemos a várias etapas:

- além da recolha de informação estatística disponível à escala do bairro, foi efectuado um levantamento funcional nos bairros em estudo, destacando-se as funçóes/serviços: locais de venda de alimentação e ménage (mini, super e hipermercados, talhos, frutarias), locais de restauração (cafés, restaurantes) e equipamentos escolares (escolas públicas de todos os ciclos e privadas até $1^{\circ}$ ciclo); 
- aplicação de inquérito a 60 agregados familiares em cada bairro, com particular atenção a inquiridos em idade activa e potencialmente com filhos dependentes, alcançando maior variedade nas dinâmicas de mobilidade e serviços procurados.

- cálculo das taxas de cobertura da populaçáo residente relativamente aos 3 funçôes / serviços estudados e considerados no levantamento funcional. Procurou-se, assim, saber qual era a percentagem de população servida a uma distância-tempo pedonal de menos e de mais de 5 minutos entre a residência e os 3 serviços / funçôes. A velocidade média de deslocação considerada foi de $3,8 \mathrm{~km} /$ hora. O levantamento funcional foi mapeado com recurso ao ArcGIS.

- por fim, comparámos os resultados obtidos com as distâncias pedonais simuladas e os resultados dos inquéritos com os comportamentos reais. Esta metodologia será explicada com maior detalhe no capítulo correspondente.

\section{OS BAIRROS EM ESTUDO - UMA BREVE CARACTERIZAÇĀO}

Como já foi referido, um dos objectivos deste projecto consistiu em ser um ensaio metodológico de verificação de algumas premissas de sustentabilidade em dois bairros, Telheiras e QC. A sua génese, os diferentes níveis de densidade populacional e a distinta localização no contexto da AML são factores que permitem explicar as diferenças existentes ao nível da morfologia urbana e das práticas familiares aferidas.

O bairro de Telheiras localiza-se em Lisboa, em duas freguesias, Lumiar e Carnide, sem delimitação administrativa. Utilizou-se assim a delimitação de Matos (inédito), composta por quatro núcleos associados a diferentes fases de expansão. No núcleo central, Aldeia de Telheiras, ainda se verifica a existência abundante de moradias. No entanto, o bairro é conhecido como um bom exemplo de planeamento urbano, já que o seu aparecimento se deve ao Plano de Urbanização de 1975, elaborado pela EPUL ${ }^{2}$. Existe no bairro um claro predomínio de prédios plurifamiliares, reflectido na sua densidade populacional (7517 $\mathrm{hab} / \mathrm{km}^{2} \mathrm{em}$ 2001), ligeiramente superior à de Lisboa $\left(6672 \mathrm{hab} / \mathrm{km}^{2}\right)$.

O bairro da QC, por sua vez, possui uma delimitaçáo oficial, pertencendo à freguesia com o mesmo nome, em Sesimbra. Além da localização no sul da AML, a freguesia está afastada do núcleo central do município. A sua génese difere do bairro de Telheiras: nos anos 70, procedeu-se ao loteamento ilegal de uma propriedade rústica para a construção de moradias individuais. Tal facto reflecte-se, ainda hoje, na morfologia do bairro e na qualidade dos espaços públicos, com o predomínio de moradias (e uma densidade populacional baixa face a Telheiras - 3536 hab/km2 em 2001, mas muito elevada face à média de Sesimbra - 192 $\mathrm{hab} / \mathrm{km}^{2}$ ) e a existência de muitos espaços vazios entre as casas. Apenas em 2006 foi aprovado o PU da QC que visa colmatar as principais lacunas existentes.

O total de 120 inquéritos realizados aos agregados familiares (60 em cada bairro) abrangeu 336 indivíduos, dos quais 36\% em Telheiras e 50\% na QC têm entre 26 e 45 anos. Nas restantes faixas etárias, observa-se que a amostra em Telheiras é mais envelhecida, com $28,66 \%$ acima dos 46 anos (contra 17,44\% na QC), enquanto no segundo bairro a percentagem de crianças até aos 15 anos é mais elevada (23,26\% contra 15,24\% em Telheiras). A

\footnotetext{
${ }^{2}$ EPUL - Empresa Pública de Urbanismo de Lisboa. De salientar, contudo, que as áreas de expansão mais recentes, embora pertencentes ao bairro, não foram obejcto desse mesmo PU.
} 
estrutura familiar, por sua vez, é semelhante nas duas amostras, com 53,3\% dos indivíduos pertencentes a famílias constituídas pelos dois cônjuges e filhos.

Devido à proximidade da Cidade Universitária e ao preço moderado das habitaçóes nos anos 70/80, Telheiras atraiu jovens licenciados e ficou conhecido como o "bairro dos Doutores”. Também o bairro da QC apresentava um preço mais baixo dos terrenos, o que atraiu população com hábitos e quotidianos urbanos mas com desejo de adquirir uma moradia individual a um menor custo. Estas diferenças estão vertidas nos resultados no que toca ao grau de instrução dos indivíduos com mais de 15 anos e às categorias profissionais: em Telheiras, $79 \%$ da amostra possui ou frequenta um grau de ensino superior, e $66 \%$ dos indivíduos são quadros superiores e profissionais intelectuais e científicos. No bairro da QC, 44\% dos indivíduos possuem ou frequentam o ensino secundário e apenas $28 \%$ possui o grau superior; a nível profissional, prevalecem os técnicos e profissionais de nível intermédio e pessoal administrativo e similares, com 53\%, e os quadros superiores e profissionais intelectuais e científicos em seguida com 19\%.

Outra das principais questôes colocadas prendeu-se com as formas de mobilidade quotidiana das famílias. Em Telheiras, 58\% dos inquiridos trabalham ou estudam no concelho e apenas 19\% fá-lo dentro do próprio bairro. Na QC, embora conhecida como um bairro dormitório, $47 \%$ da amostra trabalha ou estuda no próprio bairro; dos restantes, 33\% desloca-se diariamente para outro concelho e apenas $9 \%$ mantém-se no concelho. De salientar que estes valores incluem os estudantes, o que aumenta a percentagem de deslocaçóes dentro do próprio bairro.

Uma última questão que merece aqui destaque refere-se à participação dos cidadãos. Uma das características comuns aos dois bairros é o forte movimento associativo: em Telheiras, a Associação de Residentes constituiu um grupo de pressão influente na urbanização do bairro e, na QC, existem várias associaçóes nas áreas de actuação sócio/cultural e recreativa, sendo que ambos os bairros têm equipamentos sociais comunitários. No entanto, em ambos os bairros, apenas 6,67\% dos inquiridos afirmaram pertencer ou ter pertencido a uma associação local. O nível de participação cívica é ainda menor: apenas $5 \%$ afirmaram participar algumas ou muitas vezes em actividades de manutenção do bairro ou em assembleias da JF e da CM. Estes resultados podem influenciar o nível de proximidade dos residentes relativamente ao bairro, já que, quando se perguntou o grau de identificação ao bairro de residência, $17 \%$ e $30 \%$ responderam pouco ou nada, em Telheiras e na QC, respectivamente.

AVALIAÇÃO DOS PADRÓES DE PROCURA DE ALGUNS BENS E SERVIÇOS FREQUENTES COMO EXPRESSÃO DAS PRÁTICAS DAS FAMÍLIAS

Tal como referido, o presente ensaio procura validar apenas dois dos sete pilares - Serviços e Mobilidade. No primeiro pilar - Serviços - pressupóe-se a existência de uma boa rede/cobertura de serviços públicos, privados e comunitários, bem como uma oferta próxima e variada de comércio. No que toca ao segundo pilar em análise - Mobilidade espera-se que o bairro tenha uma boa rede de transportes públicos (intra e inter-bairros) e boas condiçóes para deslocaçóes pedonais. 
Para tal, a metodologia utilizada neste ponto foca-se na procura dos três aspectos já mencionados: locais de venda de alimentação e ménage, locais de restauração e equipamentos escolares.

De seguida, propóem-se duas leituras que se interligam: a primeira confronta as simulaçóes realizadas através da Análise de Redes (SIG) com as práticas das famílias e a segunda confronta as práticas das famílias com as percepçóes que estas têm sobre os aspectos em análise no bairro.

A primeira leitura resulta da comparação entre o potencial de população que reside a menos e a mais de 5 minutos a pé dos bens e serviços em análise e o comportamento real das famílias inquiridas Para o cálculo do potencial de população servido, recorreu-se à Análise de Redes (SIG) que permite determinar a área de cobertura e o potencial de população servida a menos de 5 minutos e a mais de 5 minutos dos 3 bens e serviços considerados (dados de Censos 2001, por subsecção estatística), tomando por base o levantamento funcional. Esta simulação é confrontada com os resultados obtidos por inquérito, resultados estes que permitem aferir os comportamentos reais das famílias, especificamente quanto à localização dos estabelecimentos procurados, tempos e modos de deslocaçáo. $\mathrm{Na}$ segunda leitura, procede-se ao confronto entre as práticas das famílias e a percepçáo que os inquiridos têm sobre alguns aspectos do seu bairro de residência, aspectos analisados a partir do inquérito realizado.

A primeira leitura - comparaçáo entre o potencial de populaçáo que reside a menos e a mais de 5 minutos a pé dos bens e serviços em análise e os valores reais relativos às práticas de utilização dos bens e serviços dos inquiridos - encontra-se sistematizada para cada bairro, analisando-se também os modos de deslocaçáo utilizados preferencialmente.

Figura 2 - Níveis de utilização de bens e serviços no Bairro de Telheiras - confronto entre o potencial de população servida a menos e a mais de 5 minutos de distância-tempo segundo o modo pedonal (simulação) e os valores reais de utilização dos bens e serviços segundo o modo de deslocação

\begin{tabular}{|c|c|c|c|c|c|}
\hline \multirow{3}{*}{ Bairro de Telheiras } & \multirow{3}{*}{$\begin{array}{c}\text { Simulação - } \\
\text { Modo } \\
\text { "a pé” (\%) }\end{array}$} & \multicolumn{4}{|c|}{ Amostra Inquiridos - Telheiras (\%) } \\
\hline & & \multirow[b]{2}{*}{ Total } & \multicolumn{3}{|c|}{ Modo de deslocação } \\
\hline & & & A pé & $\begin{array}{c}\text { Motorizado } \\
\text { próprio }\end{array}$ & $\begin{array}{c}\text { Transporte } \\
\text { Público }\end{array}$ \\
\hline \multicolumn{6}{|c|}{ Tempo $<5$ min. } \\
\hline Venda de Alimentação e Ménage & 70,6 & 5,9 & 2 & 3,9 & 0 \\
\hline Escolas & 66,5 & 14,3 & 4,8 & 4,8 & 04,8 \\
\hline Locais de Restauração & 94,6 & 12,2 & 10,2 & 2 & 0 \\
\hline \multicolumn{6}{|c|}{ Tempo > 5 min. } \\
\hline Venda de Alimentaçáo e Ménage & 29,4 & 94,1 & 29,4 & 64,7 & 0 \\
\hline Escolas & 33,5 & 85,7 & 52,4 & 33,3 & \\
\hline Locais de Restauração & 5,4 & 87,7 & 77,5 & 10,2 & 0 \\
\hline
\end{tabular}

(Elaboração própria)

Nota-se assim que, no bairro de Telheiras, a percentagem de populaçáo residente numa área a uma distância-tempo inferior a 5 minutos a pé é desigual nos três bens e 
serviços em foco. É na componente escolar que a simulação relativa ao potencial de população coberta pelo serviço e que se encontra a menos de 5 minutos é inferior (66,5\%), seguido dos locais de venda de alimentação e ménage $(70,6 \%)$ em contraste com os locais de restauração, disseminados por todo o bairro, elevando a taxa de cobertura populacional para $94,6 \%$, ou seja, praticamente toda a população do bairro tem um estabelecimento de restauração na proximidade da sua casa (menos de 5 minutos a pé).

Porém, apesar dos elevados potenciais, o comportamento das famílias inquiridas revela-se díspar dos valores teóricos, já que são uma minoria as famílias que demoram menos de 5 minutos nas suas deslocaçáo para as três componentes. Além desta discrepância, outro fenómeno observado diz respeito ao meio de deslocação utilizado: mesmo para percursos inferiores a 5 minutos dentro do bairro de residência, há indivíduos que o fazem de automóvel ou outro veículo motorizado próprio. Se, por um lado, na procura de cafés e restaurantes a maioria dos inquiridos vai a pé, já no que toca à procura de locais de venda de alimentação há uma maior utilização do automóvel. Nas deslocações a menos de 5 minutos para as escolas, os modos de deslocação têm todos o mesmo peso $(4,8 \%)$ em que, além de ir a pé ou de automóvel, surgem também os transportes públicos.

Quando observado o comportamento das famílias que demoram na realidade mais de 5 minutos na deslocação para estas actividades, verificamos que a quase totalidade poderia executar a deslocaçáo em menos de 5 minutos, muito embora a maioria dos indivíduos que frequentam a escola ou procuram locais de restauração o façam a pé $(52,4 \%$ no primeiro e $77,5 \%$ no segundo caso). Os $33 \%$ de indivíduos que vão para a escola em veículos motorizados próprios são maioriamente crianças e jovens levados na viatura dos pais, que seguem depois para o local de emprego. Por fim, no que respeita à procura de locais de venda de alimentaçáo, dos $94,1 \%$ dos inquiridos que o fazem no bairro e demoram mais de 5 minutos, 64,7\% fazem-no de automóvel. Sabendo que a maioria das famílias realiza as compras alimentares em grandes superfícies, com facilidade de estacionamento e, por vezes, com acessos pedestres difíceis (incitando ainda mais a utilização do automóvel), surge como «natural» a opção tomada.

No segundo bairro em análise - QC - e em comparação com Telheiras, observa-se que a percentagem de população a menos de 5 minutos a pé é inferior para os locais de venda de alimentação (61,2\% na QC), bastante inferior no que toca às escolas $(43,5 \%)$ mas um pouco superior quando se refere a locais de restauraçáo $(96,8 \%)$.

Quanto aos modos de deslocação, se há um paralelismo com o primeiro bairro nas deslocaçóes para locais de venda de alimentaçáo (com predominância de utilização de veículos motorizados próprios) e para os locais de restauração (principalmente deslocaçóes pedestres), encontra-se uma diferença nas deslocaçóes para as escolas.

Efectivamente, $36,1 \%$ dos indivíduos demora menos de 5 minutos, valor que se aproxima do calculado (43,5\%). No entanto, apenas $16,7 \%$ vai a pé, sendo que os outros $19,4 \%$ deslocam-se em viatura motorizada própria. As razóes para tal facto podem ser as mesmas que para o bairro anterior, aliadas ao mau estado do espaço público, mas pode ainda depender da própria análise efectuada, uma vez que a escola próxima de casa pode náo ser a adequada para a idade do estudante ${ }^{3}$.

\footnotetext{
${ }^{3}$ Daqui decorre desde já uma recomendação/correcção metodológica a ter em conta em trabalhos futuros e que se relaciona com a necessidade de segmentar o nível de ensino a que corresponde o estabelecimento, de
} 
Figura 3 - Níveis de utilização de bens e serviços no Bairro da Quinta do Conde confronto entre o potencial de população servida a menos e a mais de 5 minutos de distância-tempo segundo o modo pedonal (simulação) e os valores reais de utilização dos bens e serviços segundo o modo de deslocação

\begin{tabular}{|c|c|c|c|c|c|}
\hline \multirow{3}{*}{ Quinta do Conde } & \multirow{3}{*}{$\begin{array}{l}\text { Simulaçáo - } \\
\text { Modo } \\
\text { “a pé” (\%) }\end{array}$} & \multicolumn{4}{|c|}{$\begin{array}{c}\text { Amostra Inquiridos - Quinta do Conde } \\
(\%)\end{array}$} \\
\hline & & \multirow[b]{2}{*}{ Total } & \multicolumn{3}{|c|}{ Modo de deslocação } \\
\hline & & & A pé & $\begin{array}{c}\text { Motorizado } \\
\text { próprio }\end{array}$ & $\begin{array}{c}\text { Transporte } \\
\text { Público }\end{array}$ \\
\hline \multicolumn{6}{|c|}{ Tempo $<5$ min. } \\
\hline Venda de Alimentação e Ménage & 61,2 & 14,0 & 5,3 & 8,8 & 0 \\
\hline Escolas & 43,5 & 36,1 & 16,7 & 19,4 & 0 \\
\hline Locais de Restauração & 96,8 & 14 & 11,6 & 2,3 & 0 \\
\hline \multicolumn{6}{|c|}{ Tempo $>5$ min. } \\
\hline Venda de Alimentação e Ménage & 38,8 & 86,0 & 12,3 & 73,7 & 0 \\
\hline Escolas & 56,5 & 63,9 & 30,6 & 27,8 & 5,6 \\
\hline Locais de Restauração & 3,2 & 86 & 53,5 & 32,6 & 0 \\
\hline
\end{tabular}

(Elaboração própria)

Nota-se também que a grande maioria dos inquiridos afirma demorar mais de 5 minutos na procura dos 3 tipos de bens e serviços. O modo de deslocação preponderante é bastante diferente consoante o tipo de procura: a maioria dos inquiridos desloca-se de automóvel para a procura de locais de alimentação e ménage (73,7\% no total de $86 \%$ ), na procura de cafés e restaurantes a deslocação pedonal é maioritariamente superior $(53,5 \%)$ à deslocação motorizada $(32,6 \%)$ e, por fim, para a escola, os comportamentos repartemse entre a deslocação pedestre (30,6\%) e de automóvel (27,8\%).

A segunda leitura resulta do confronto entre as práticas das famílias e as suas percepçóes sobre o bairro, informação que foi igualmente obtida por inquérito, que continha questôes sobre a percepção que os indivíduos têm do seu bairro de residência.

Assim, relativamente à questáo "Como avalia a qualidade de vida no bairro?", a percentagem de respostas negativas (Qualidade de Vida "Má" ou "Muito Má”) são nulas no bairro de Telheiras e muito reduzidas na QC (1,7\%). Mais ainda, em Telheiras, 68,3\% dos inquiridos consideram ter "Boa" ou "Muito Boa" qualidade de vida e, na QC, 48,3\%.

Para além da questão anterior, consideraram-se outras 3 questóes mais específicas: a qualidade do serviço de transportes públicos, o nível de comércio e serviços e a existência de condiçóes para andar a pé. Quanto ao serviço de transportes públicos, 75,9\% dos inquiridos em Telheiras considera que o bairro está bem ou muito bem servido, ao contrário dos inquiridos na QC, onde 42,9\% avalia o bairro como estando mal ou muito mal servido de Transportes Públicos. Se, na QC, a avaliação reflecte o modo de deslocação preferencial - automóvel, já em Telheiras há uma discrepância entre a percepção que os residentes têm do serviço (que consideram que os transportes públicos têm um bom nível) e do modo de deslocação que escolhem diariamente (forte utilização do automóvel). Podemos ainda sublinhar que $90 \%$ dos telheirenses inquiridos que utilizam os transportes

forma a poder articular essa análise com a informação obtida por inquérito (e onde à possível considerar a idade dos descendentes e articulá-la ao nível do estabelecimento de ensino). 
públicos para deslocaçóes laborais encontram-se satisfeitos, enquanto que, na QC, 49\% dos indivíduos que se deslocam a pé e $55 \%$ dos que utilizam transportes públicos estão insatisfeitos com a rede existente.

No que respeita à avaliação do bairro quanto a existência de comércio e serviços, as percentagens são exactamente iguais para ambos os bairros: $36,8 \%$ dos inquiridos estão satisfeitos. Assim, e apesar de ser maior a percentagem que considera haver pouco comércio e serviços, a maioria dos inquiridos procura os vários serviços (bancos, correios, etc) a pé: 95\% em Telheiras e 66\% na QC.

Para terminar, mais de metade dos inquiridos avalia as condiçóes para andar a pé como positivas: 67,8\% em Telheiras e 51,7\% na QC (sendo que neste bairro existem 13,3\% de inquiridos insatisfeitos). Quando analisado por local de trabalho, verifica-se que quem sai do bairro avalia este aspecto de forma mais positiva do que os que residem e trabalham no bairro.

\section{Algumas ReFleXÓEs Finais}

Não esquecendo que a análise é parte integrante de um trabalho mais completo, onde se abordaram itens relativos aos comportamentos e escolhas familiares à escala do bairro que potenciam uma comunidade mais ou menos sustentável, surgem, no entanto, algumas ideias-chave que importa sublinhar. A primeira prende-se com a densidade populacional uma maior densidade e concentração populacional facilita a optimização da rede de equipamentos e a proximidade de maior percentagem de população ao serviço, bem como à rede de transportes públicos. A uma maior densidade associa-se também o potenciar das deslocações a pé de curta duração.

O segundo aspecto está relacionado com a localizaçáo dos bairros no concelho e na AML, revelando-se fulcral para a aproximação das comunidades aos pressupostos sustentáveis, como se pode inferir pelos resultados aqui apresentados.

$\mathrm{O}$ terceiro aspecto prende-se com a morfologia do bairro e a sua envolvente no que toca à rede de equipamentos, serviços, comércio, redes viárias e de transportes, postos de trabalho, entre outros aspectos, que permitem às famílias uma maior ou menor escolha e a adopção de práticas quotidianas que dependem não só do nível de serviços do bairro, mas também do local de trabalho e do tipo de actividade desempenhada pelos vários membros do agregado. Assim, além do nível de serviços disponíveis, a questão da acessibilidade mostra-se também ser um factor relevante para as escolhas das famílias no que toca aos modos de deslocação escolhidos.

Porém não são só os factores morfológicos e locativos que interferem na sustentabilidade da comunidade, mas também as novas práticas quotidianas das famílias e as novas formas de uso do tempo, que revelam ser extremamente influenciadoras das componentes associadas à sustentabilidade - local de aquisição/frequência de bens e serviços, modos de transporte e tempos de deslocação. Actualmente verifica-se que a proximidade à residência pode não ser o requisito-base para o cumprimento dos pressupostos sustentáveis. O local de trabalho ou as questóes de "gosto» vêm alterar o padrão de aquisição de bens e serviços. Outra variável com influência é o ciclo de vida das famílias tal como a existência de filhos, especialmente em idade escolar, e ainda o rendimento do agregado e a situaçáo académica e profissional, que não deixam de ser estruturantes. 
Assim, torna-se fundamental a valorização do bairro para pensar e fazer planeamento urbano, procurando melhorar a rede de equipamentos básicos, de espaços de lazer e convívio, de habitação variada e de transportes e acessibilidades, de acordo com as densidades populacionais e urbanísticas, promovendo, desta forma, práticas quotidianas mais sustentáveis.

\section{REFERÊNCIAS BIBLIOGRÁFICAS}

Autoridades Locais Europeias 2004, Aalborg +10, Inspirando o Futuro, Conferência Aalborg +10, Aalborg. Consulta Set. 2009. Disponível em: http://www.anmp.pt/anmp/doc/div/2005/age21/docs/a22.pdf

C.N.U. 2001, Charter of the New Urbanism, CNU IV, 1996, Charleston. Consulta Set. 2009. Disponível em: http://www.cnu.org/charter

Matos, F. (inédito), Que potencial de uma associação de residentes para a governança urbana - caso de estudo a Associação de Residentes de Telheiras. Sem. Geog. Humana - fim de licenciatura no curso de Geografia, Jul/2009, FLUL, Lisboa

O.D.P.M. 2004, The Egan Review - Skills for Sustainable Communities, Crown, London. Consulta Set. 2009. Disponível em: http://www.communities.gov.uk/publications/communities/eganreview 